\title{
Compassion Fatigue, Compassion Satisfaction, and Burnout in Oncology Nurses: A Systematic Review and Meta-Analysis
}

\author{
Elena Ortega-Campos ${ }^{1}$, Keyla Vargas-Román ${ }^{2}{ }^{\mathbb{D}}$, Almudena Velando-Soriano ${ }^{3}$, \\ Nora Suleiman-Martos ${ }^{4}\left(\mathbb{D}\right.$, Guillermo A. Cañadas-de la Fuente ${ }^{5}$, , Luis Albendín-García ${ }^{6, *(1)}$ \\ and José L. Gómez-Urquiza 5 \\ 1 Faculty of Psychology, University of Almería, Carretera de Sacramento s/n, 04120 Almería, Spain; \\ elenaortega@ual.es \\ 2 Faculty of Psychology, University of Granada, Campus Universitario de Cartuja s/n, 18071 Granada, Spain; \\ keyvarom@ugr.es \\ 3 ZBS Benamaurel, Northeast District of Granada, Andalusian Health Service, 18817 Granada, Spain; \\ srtavelando@gmail.com \\ 4 Faculty of Health Sciences, University of Granada, Calle Cortadura Del Valle S.N., 51001 Ceuta, Spain; \\ norasm@ugr.es \\ 5 Faculty of Health Sciences, University of Granada, Avenida de la Ilustración, 60, 18016 Granada, Spain; \\ gacf@ugr.es (G.A.C.-d.1.F.); jlgurquiza@ugr.es (J.L.G.-U.) \\ 6 La Chana Health Center, Granada Metropolitan District, Andalusian Health Service, Calle Virgen de la \\ Consolación, 12, 18015 Granada, Spain \\ * Correspondence: lualbgar1979@ugr.es
}

Received: 28 October 2019; Accepted: 17 December 2019; Published: 20 December 2019

\begin{abstract}
Professionals working in cancer care are exposed to strong sources of stress. Due to the special characteristics of this unit, the appearance of burnout, compassion fatigue, and low compassion satisfaction is more likely. The principal aim was to analyze the levels and prevalence of burnout, compassion fatigue, and low compassion satisfaction in oncology nurses and interventions for its treatment. The search for the systematic review was done in Medline, ProQuest, Lilacs, CINAHL, Scopus, Scielo, and PsycINFO databases, with the search equation "burnout AND nurs" AND oncology AND compassion fatigue". The results obtained from the 15 studies confirmed that there are levels of risk of suffering burnout and compassion fatigue among nursing professionals, affecting more women and nurses with more years of experience, with nurses from oncology units having one of the highest levels of burnout and compassion fatigue. The oncology nurse sample was $n=900$. The meta-analytic estimations were $19 \%$ for low compassion satisfaction, $56 \%$ for medium and high burnout, $\mathrm{BO}$, and $60 \%$ for medium and high compassion fatigue. The increase in cases of burnout and compassion fatigue in nursing staff can be prevented and minimized with a correct evaluation and development of intervention programs, considering that there are more women than men and that they seem to be more vulnerable.
\end{abstract}

Keywords: burnout; compassion fatigue; meta-analysis; nurses; oncology; oncology nurses; systematic review

\section{Introduction}

Work in the healthcare field is characterized by the presence of numerous factors that can cause stress in different work environment areas (psychological, social, and work). The development of chronic stress in healthcare professionals can consequently lead to the appearance of burnout syndrome, 
characterized by the presence of emotional exhaustion, depersonalization in the treatment of patients, and a low personal accomplishment [1-3].

Burnout has negative effects for healthcare professionals (insomnia, irritability, etc.) and also in the workplace, like absenteeism, temporary work disability, deterioration of patient care, or more errors in the job. Recently, this syndrome has been recognized as an occupational disease by being included in the International Classification of Diseases (ICD-11) of the World Health Organization [4].

Burnout has a high prevalence in healthcare professionals, although nurses are an important risk group. In fact, there are numerous studies about the possible influence of socio-demographic factors and the work environment as a starting point for nursing burnout development [5-7]. The particularity of the work and patient assistance in each unit is important for the study of burnout in nurses because it can change the risk of burnout development, as it has been shown in studies in pediatric services [8], obstetrics/gynecology [9], psychiatry [10], emergencies [6,11], and especially in oncology [12-15].

The care of patients in oncology units is emotionally exhausting [16]. Oncology nurses deal daily with the pain of patients and their family members. Repeated exposure to situations with a high emotional load can cause oncology nurses to show compassion fatigue [17]. The term compassion fatigue describes the physical, mental distress, and exhaustion derived from the care of others [18]. Nurses with compassion fatigue have physical and emotional symptoms as well as exhaustion that negatively affect them in performing their job correctly [19].

Oncology units need a detailed study of the particularities presented by nurses working in this unit in relation with compassion fatigue, compassion satisfaction, and burnout [11,13-15]. Daily contact with people with long-term and deadly diseases means that oncology nurses face suffering, death, and the grieving processes of family members daily.

In the absence of an updated review of compassion fatigue in oncology nurses, the aim of this work was to analyze the levels and prevalence of compassion fatigue, compassion satisfaction, and burnout in oncology nurses, and interventions for its treatment.

\section{Material and Methods}

\subsection{Information Resources, Search Equation, and Inclusion/Exclusion Criteria}

This systematic review was conducted following PRISMA recommendations (Preferred Reporting Items for Systematic Reviews and Meta-Analyzes) [20]. The first step was the search using the following electronic databases: Cinahl, Lilacs, ProQuest, PsyCinfo, Medline, Scielo, and Scopus.

The keywords were selected using the Medical Subject Headings tool of the National Library of Medicine and the following descriptors were obtained: "Burnout" "nurs" "oncology" "compassion fatigue". The search equation used in this review was: Burnout AND nurs* AND oncology AND compassion fatigue.

The inclusion criteria for the selection of the studies were: (a) Empirical studies; (b) publication language: English or Spanish; (c) oncology nurses sample; (d) indicated a compassion fatigue measure in the study; and (e) included a prevalence rate of compassion fatigue, compassion satisfaction, and burnout. The search was performed without a temporary limitation.

The exclusion criteria for the selection of studies were: (a) Review articles: Systematic reviews and/or meta-analysis; (b) studies using the same sample; (c) articles with nursing students; and (d) final studies (degree, master and thesis).

\subsection{Variables}

The variables were recorded on a data definition log. Two members of the research team independently performed the search and selection of the studies. In the case of disagreement, a third researcher was consulted. The following variables were considered:

Publication variables: (a) Authors; (b) year of publication; (c) country of publication; (d) language (Spanish, English); (e) sample size; and (f) percentage of female nurses in the sample. 
Methodological variables: (g) Instrument for compassion fatigue, compassion satisfaction, and burnout measurement.

Compassion fatigue, compassion satisfaction, and burnout-related variables: (h) Main results for the presence of compassion fatigue, compassion satisfaction, and burnout in oncology nurses, including: (i) Prevalence of low, medium, and high levels of compassion fatigue, compassion satisfaction, and burnout.

\subsection{Procedures}

The search was conducted in September 2019. Figure 1 shows the studies that were reviewed in each phase. A total of 328 documents were located after the search. Then, after reviewing the title and abstract, 217 documents were excluded because they did not meet the inclusion criteria. Finally, after evaluating 81 full texts, the sample was composed of 15 studies for the systematic review and 5 for the meta-analysis.

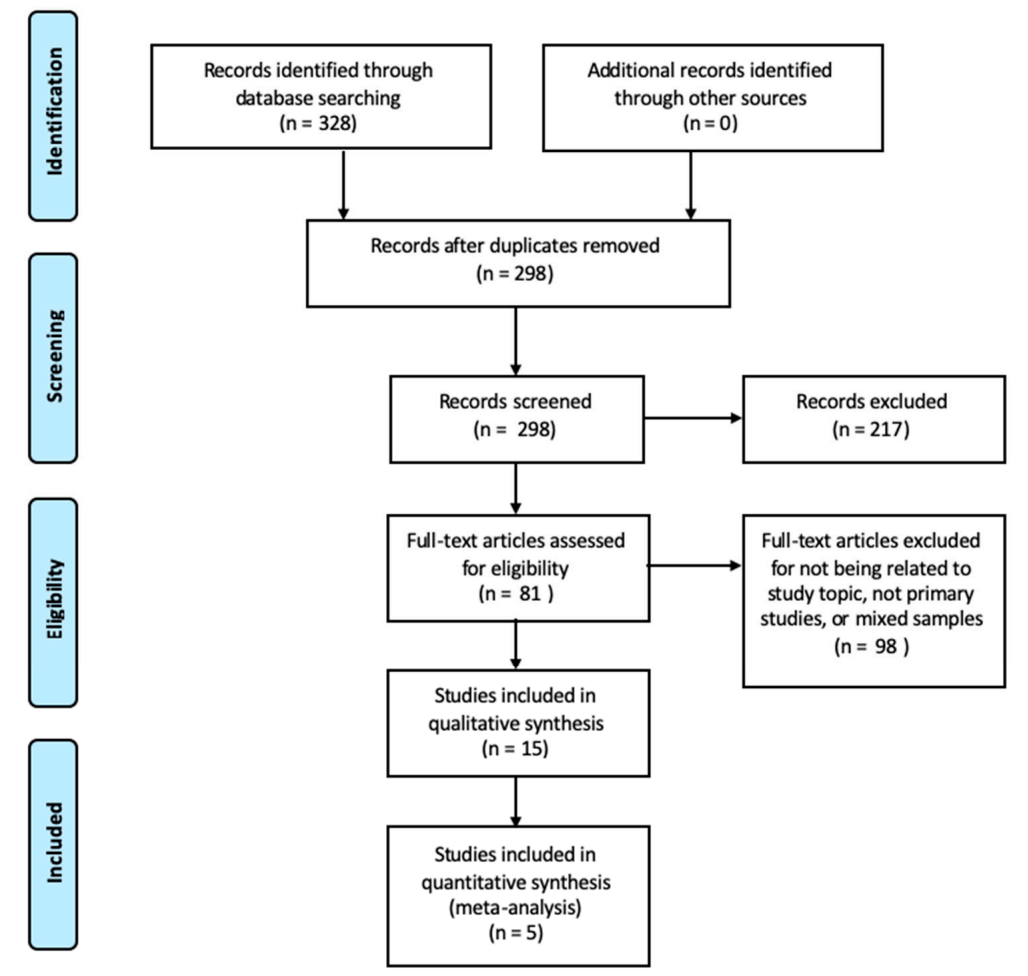

Figure 1. Flowchart of the study selection process.

To assess the quality of the included studies, the evidence and recommendation levels of the Oxford Center for Evidence-based Medicine [21] were followed.

\subsection{Data Analysis}

The meta-analysis was done with the software StatsDirect. Three random effects proportion meta-analysis were done to calculate an estimation of the prevalence rate of low compassion satisfaction, medium and high burnout, and medium and high compassion fatigue. Publication bias was evaluated with Egger test and heterogeneity with $I^{2}$.

\section{Results}

\subsection{Characteristics of the Selected Studies}

A total of $n=15$ studies were obtained from the search (Table 1). The samples of these studies included nurses working in oncology units and the majority of the subjects were women. 
Table 1. Studies obtained from the research.

\begin{tabular}{|c|c|c|c|c|c|c|c|}
\hline Study & Design & Sample & Instrument & Data Medium (SD) & Results & LE & GR \\
\hline $\begin{array}{l}\text { Al-Majid et al. } \\
\text { (2018). USA }\end{array}$ & $\begin{array}{l}\text { Cross-sectional } \\
\text { study }\end{array}$ & $N=26$ oncology nurses & ProQOL-5 & $\begin{array}{c}\text { Compassion Satisfaction } 52.0(9.6) \\
\text { Burnout } 49.2(9.2) \\
\text { STS } 51.4(10.0)\end{array}$ & $\begin{array}{l}\text { The low CF scores of the nurses in the study can be } \\
\text { explained by the recent training received in the } \\
\text { hospital in the identification and recognition of CF } \\
\text { by nurses. } \\
\text { The results of the study indicate that CS was } \\
\text { significantly higher in nurses with more than } 10 \\
\text { years of experience. This may suggest that nurses } \\
\text { develop resilience to job stressors the longer they } \\
\text { work. }\end{array}$ & $2 c$ & B \\
\hline $\begin{array}{l}\text { Duarte et al. } \\
\text { (2016). Portugal }\end{array}$ & $\begin{array}{l}\text { Quasi-experimental } \\
\text { intervention study }\end{array}$ & $\begin{array}{l}\mathrm{N}=48 \text { oncology nurses } \\
\text { Experimental group }=29 \\
\quad \text { control Group }=19\end{array}$ & ProQOL-5 & 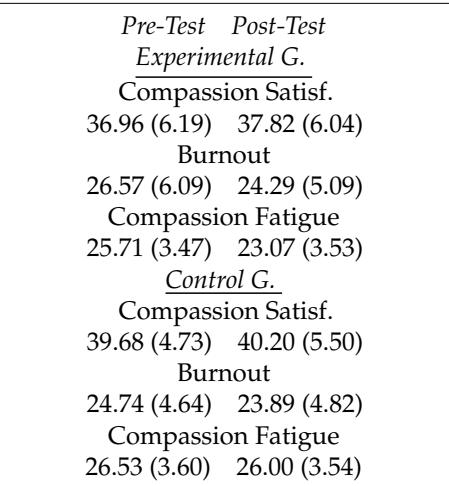 & $\begin{array}{l}\text { The results indicate that nurses in the experimental } \\
\text { group show significant decreases in compassion } \\
\text { fatigue and burnout, and increased satisfaction with } \\
\text { life, mindfulness and self-compassion, presenting } \\
\text { medium to large effect sizes. No significant changes } \\
\text { were found in any of the variables studied in the } \\
\text { nurses of the control group. } \\
\text { The results of the study provide preliminary } \\
\text { evidence on the efficacy of mindfulness-based } \\
\text { interventions in reducing burnout and Compassion } \\
\text { Fatigue in Oncology nurses. }\end{array}$ & $1 \mathrm{~b}$ & A \\
\hline $\begin{array}{l}\text { Duarte et al. } \\
\text { (2017). Portugal }\end{array}$ & $\begin{array}{c}\text { Cross-sectional } \\
\text { study }\end{array}$ & $N=221$ oncology nurses & ProQOL-5 & CS $38.00(5.41)$ & $\begin{array}{l}\text { Most of the Oncology nurses in this study have } \\
\text { medium or high scores in CS, Burnout or CF. } \\
\text { Constant exposure to the pain of others causes } \\
\text { Oncology nurses to have high scores in these } \\
\text { variables. The study authors recommend } \\
\text { performing interventions based on psychological } \\
\text { variables for the improvement of CS, Burnout and } \\
\text { CF in Oncology nurses. }\end{array}$ & & \\
\hline $\begin{array}{l}\text { Hevezi et al. } \\
\text { (2016). USA }\end{array}$ & $\begin{array}{l}\text { Quasi-experimental } \\
\text { intervention study }\end{array}$ & $N=15$ oncology nurses & ProQOL-5 & $\begin{array}{c}\text { Mean-Before vs. Mean-After } \\
\text { Compassion satisfaction } 36.6 \text { vs. } 39.3 \\
\text { Burnout } 26.4 \text { vs. } 22.2 \\
\text { Secondary trauma score } \\
25.3 \text { vs. } 22.2\end{array}$ & $\begin{array}{l}\text { The results indicate that the intervention performed } \\
\text { to the Oncology nurses decreased the scores } \\
\text { presented in Burnout and Compassion Fatigue, and } \\
\text { increases the scores in Compassion Satisfaction. }\end{array}$ & $1 \mathrm{~b}$ & $\mathrm{~A}$ \\
\hline
\end{tabular}


Table 1. Cont.

\begin{tabular}{|c|c|c|c|c|c|c|c|}
\hline Study & Design & Sample & Instrument & Data Medium (SD) & Results & LE & GR \\
\hline $\begin{array}{l}\text { Hooper et al. } \\
\text { (2010). USA }\end{array}$ & $\begin{array}{l}\text { Cross-sectional } \\
\text { study }\end{array}$ & 12 oncology nurses & ProQOL R-IV & $\begin{array}{c}\text { Oncology n (\%) } \\
\text { Compassion satisfaction } \\
\text { Low: } 1 \text { (8.3); Medium: } 5 \text { (41.7); High: } \\
\text { 6(50.0) } \\
\text { Burnout } \\
\text { Low: } 2 \text { (16.7); Medium: } 7 \text { (58.3); High: } 3 \\
\text { (25.0) } \\
\text { Compassion fatigue } \\
\text { Low: } 3 \text { (25.0); Medium: } 5 \text { (41.7); High } \\
\text { (>17): } 4 \text { (33.3) }\end{array}$ & $\begin{array}{l}\text { Despite being a study with a small sample, the } \\
\text { status of the Oncology nurses can be seen in the } \\
\text { results. Among the most outstanding results, less } \\
\text { than } 10 \% \text { of nurses have a low level of Compassion } \\
\text { Satisfaction. In relation to Burnout, more than } 80 \% \\
\text { of nurses have medium or high levels. Finally, } 25 \% \\
\text { of Oncology nurses have low levels of Compassion } \\
\text { Fatigue. }\end{array}$ & $2 c$ & B \\
\hline $\begin{array}{c}\text { Jakel et al. (2016). } \\
\text { USA. }\end{array}$ & $\begin{array}{l}\text { Quasi-experimental } \\
\text { Pre-post test }\end{array}$ & $\begin{array}{l}\mathrm{N}=25 \text { oncology nurses } \\
\text { Intervention: } \mathrm{N}=16 \\
\text { Control: } \mathrm{N}=9\end{array}$ & ProQOL-5 & $\begin{array}{c}\text { M Pretest vs. Post-Test } \\
\text { STS } \\
\text { Intervention } 23.06 \text { vs. } 21.75 \\
\text { Control } 25 \text { vs. } 23.78 \\
\text { CS } \\
\text { Intervention } \quad 42.63 \text { vs. } 41.19 \\
\text { Control } \quad 41.44 \text { vs. } 42.78 \\
\text { Burnout } \\
\text { Intervention } \quad 20.25 \text { vs. } 21.38 \\
\text { Control } \quad 21.67 \text { vs. } 21.67\end{array}$ & $\begin{array}{l}\text { The authors implemented in this pilot study in the } \\
\text { intervention group the use of a mobile app that } \\
\text { works on the resilience of Oncology nurses. } \\
\text { More studies are needed to analyze the use of new } \\
\text { technologies in the prevention of CF and Burnout, } \\
\text { as well as to promote Resilience. }\end{array}$ & $1 b$ & A \\
\hline $\begin{array}{c}\text { Jang et al. (2016). } \\
\text { South Korea }\end{array}$ & $\begin{array}{c}\text { Cross-sectional } \\
\text { study }\end{array}$ & 285 oncology nurses & ProQOL-5 & $\begin{array}{l}\text { CS: } 33.84(5.62) \\
\text { Burnout: } 28.38(5.36) \\
\text { STS: } 28.33(5.48)\end{array}$ & $\begin{array}{l}\text { The results of the study show that South Korean } \\
\text { Oncology nurses have medium or high scores in CS, } \\
\text { Burnout and STS. Less than } 30 \% \text { of nurses have low } \\
\text { values in CS, Burnout and STS. }\end{array}$ & $2 c$ & B \\
\hline $\begin{array}{l}\text { Mooney et al. } \\
\text { (2017). USA }\end{array}$ & $\begin{array}{l}\text { Cross-sectional } \\
\text { study }\end{array}$ & $\mathrm{N}=18$ oncology nurses & ProQOL & $\begin{array}{l}\text { CS: } 41.2(4.15) \\
\text { Burnout: } 23.3(2.80) \\
\text { CF: } 20.3(4.61)\end{array}$ & $\begin{array}{l}\text { Taking in consideration the cut-off points of the } \\
\text { ProQOL scale, the nurses of this work have high } \\
\text { levels of CS and Burnout and low levels of CF. }\end{array}$ & $2 c$ & B \\
\hline $\begin{array}{l}\text { Potter et al. (2013). } \\
\text { USA }\end{array}$ & Cohort study & $\mathrm{N}=13$ oncology nurses & ProQOL IV & $\begin{array}{c}\text { Compassion satisfaction (M) } \\
\text { Before: } 39.53 \\
\text { After: } 39.92 \\
3 \text { months after: } 38.53 \\
6 \text { months after: } 40.76 \\
\text { Burnout } \\
\text { Before: } 23.46 \\
\text { After: } 22.61 \\
3 \text { months after: } 23.69 \\
6 \text { months after: } 22.3 \\
\text { Secondary trauma } \\
\text { Before: } 19.76 \\
\text { After: } 17.61 \\
3 \text { months after: } 17.92 \\
6 \text { months after: } 16.23\end{array}$ & $\begin{array}{l}\text { The nurses in the study conducted a } 4 \text {-session } \\
\text { program to improve Resilience. The scores in CS, } \\
\text { Burnout and STS improved after the program, } \\
\text { especially the STS score. } \\
\text { The Development/promotion of Resilience towards } \\
\text { CF can improve the satisfaction of nurses. }\end{array}$ & $2 c$ & B \\
\hline
\end{tabular}


Table 1. Cont.

\begin{tabular}{|c|c|c|c|c|c|c|c|}
\hline Study & Design & Sample & Instrument & Data Medium (SD) & Results & LE & $\overline{G R}$ \\
\hline $\begin{array}{l}\text { Wells et al. (2019). } \\
\text { USA }\end{array}$ & $\begin{array}{l}\text { Cross-sectional } \\
\text { study }\end{array}$ & $\mathrm{N}=93$ oncology nurses & ProQOL-V & $\begin{array}{l}\text { CS: } 40.12(6.20) \\
\text { Burnout: } 23.72(5.09) \\
\text { STS: } 21.93(5.25)\end{array}$ & $\begin{array}{l}\text { The relationship between Burnout and CS }(\mathrm{r}= \\
-0.68) \text {, Burnout and STS }(\mathrm{r}=0.57) \text { and CS and STS }(\mathrm{r} \\
=-0.29) \text {. The authors recommend the } \\
\text { implementation of strategies to reduce CF both } \\
\text { individually and organizationally, which would } \\
\text { improve the well-being of the patient and oncology } \\
\text { nurses. }\end{array}$ & $2 c$ & B \\
\hline $\begin{array}{l}\text { Wu et al. (2016) } 1 \\
\text { USA }\end{array}$ & $\begin{array}{l}\text { Cross-sectional } \\
\text { study }\end{array}$ & $\mathrm{N}=486$ oncology nurses & ProQOL & $\begin{array}{l}\text { CS: } 42.37(5.27) \\
\text { Burnout: } 22.66(5.74) \\
\text { STS: } 22.65(5.77)\end{array}$ & $\begin{array}{l}\text { The Oncology nurses of this work have a high risk } \\
\text { of CS and low risk through Burnout and STS. }\end{array}$ & $2 c$ & B \\
\hline $\begin{array}{l}\text { Wu et al. (2016) } 2 \\
\text { Canada }\end{array}$ & $\begin{array}{l}\text { Cross-sectional } \\
\text { study }\end{array}$ & $N=63$ oncology nurses & ProQOL & $\begin{array}{l}\text { CS: } 42.6(4.7) \\
\text { Burnout: } 22.49(4.84) \\
\text { STS: } 22.41(5.6)\end{array}$ & $\begin{array}{l}\text { In this work, the authors indicate that Oncology } \\
\text { nurses have a high level of CS and a low level of } \\
\text { Burnout and STS. }\end{array}$ & $2 c$ & B \\
\hline $\begin{array}{l}\text { Yilmaz et al. } \\
\text { (2018). Turkey. }\end{array}$ & $\begin{array}{l}\text { Quasy-experimental } \\
\text { study }\end{array}$ & $\mathrm{N}=43$ oncology nurses & ProQOL & $\begin{array}{c}\text { CF pretest } 24.95(6.38) \\
\text { CF posttest } 12.00(4.54) \\
\text { Burnout pretest } 27.32(3.14) \\
\text { Burnout posttest } 12.97(4.06) \\
\text { CS pretest } 32.67(7.07) \\
\text { CS posttest } 41.93(5.00) \\
\end{array}$ & $\begin{array}{l}\text { A nurses-led intervention program with two } \\
\text { sessions (lecture, reading and video about CF and } \\
\text { coping, exercise, baksi dance, mandala painting) } \\
\text { and two counselling follow-ups (motivational } \\
\text { messages via smartphone) is effective to reduce CF } \\
\text { and burnout and increase CS. }\end{array}$ & $1 \mathrm{~b}$ & A \\
\hline $\begin{array}{l}\text { Yu et al. (2016). } \\
\text { China. }\end{array}$ & $\begin{array}{l}\text { Cross-sectional } \\
\text { study }\end{array}$ & $N=650$ oncology nurses & ProQOL & $\begin{array}{l}\text { CS: } 31.81(6.49) \\
\text { Burnout: } 21.14(4.95) \\
\text { CF: } 21.39(4.84)\end{array}$ & $\begin{array}{l}\text { The results of the study indicate that nurses who } \\
\text { have more years of work experience and adopt } \\
\text { passive coping strategies have higher levels of } C F \\
\text { and Burnout. }\end{array}$ & $2 c$ & B \\
\hline $\begin{array}{l}\text { Zajac et al. (2017). } \\
\text { USA }\end{array}$ & $\begin{array}{l}\text { Mixed-methods } \\
\text { study }\end{array}$ & $n=91$ & PRoQOL-5 & $\begin{array}{l}\text { PRE POST } \\
\text { CS: } 40.62 \text { vs. } 41.02 \\
\text { Burnout: } 22.51 \text { vs. } 21.9 \\
\text { STS: } 24.7 \text { vs. } 23.44\end{array}$ & $\begin{array}{l}\text { Oncology nurses have average scores in CS and STS } \\
\text { and low in Burnout. No statistically significant } \\
\text { differences were found between pre and post scores. } \\
\text { The authors recommend nurses to attend } \\
\text { workshops on CF and its intervention and } \\
\text { management of the phenomenon. }\end{array}$ & $1 \mathrm{~b}$ & A \\
\hline
\end{tabular}

CS = Compassion Satisfaction; CF = Compassion Fatigue; STS = Secondary Traumatic Stress; LE = Level of Evidence; GR = Grade of Recommendation. 
Regarding the methods of the included studies, nine had a cross-sectional design [22-29], four had a quasi-experimental design [30-33], and one study had a cohort design [34].

All studies used the Professional Quality of Life Scale (ProQOL) instrument [18], which measures compassion fatigue, compassion satisfaction, and burnout. Compassion satisfaction and fatigue due to compassion are aspects of working life. The instrument is composed of three scales: Compassion satisfaction, burnout, and secondary traumatic stress. The burnout and secondary traumatic scales together allow measurement of compassion fatigue.

\subsection{Prevalence of Burnout and Compassion Fatigue}

Three studies provided data on the level and prevalence of compassion satisfaction and burnout in oncology nurses [23-25]. The prevalence of compassion fatigue and burnout did not exceed $35 \%$ in oncology nurses. In the study by Duarte et al. [23], they informed of a high level of burnout $(26.7 \%)$ and compassion fatigue (24.9\%). Hooper et al. [24] indicated a high level of burnout in $25 \%$ and compassion fatigue in 33.3\%. Finally, in Jang et al. [25], the data indicated a high level of burnout in $24.6 \%$ and secondary traumatic stress in $27.4 \%$.

One cross-sectional studies showed high average scores for burnout (49.2) and secondary traumatic stress (51.4) [22]. The rest of the studies indicated medium average scores between 20 and 29 for burnout, secondary traumatic stress, or compassion fatigue [23,25-29].

\subsection{Interventions for Reducing Compassion Fatigue}

Five studies did an intervention to improve compassion fatigue in oncology nurses. Four studies applied an intervention with pre-test and post-test measures [30-33], and one had a follow-up at 3 and 6 months [34].

Regarding the interventions, Duarte et al. [30] performed an intervention of six weeks with a duration of $2 \mathrm{~h}$ per week for each session, based on mindfulness. Each session included a didactic session on topics related to mindfulness and meditation exercises. The participants were encouraged to practice meditation for, at least, $15 \mathrm{~min}$ a day. The results indicated that nurses in the experimental group had lower scores in compassion fatigue and burnout, and higher levels of satisfaction with life, mindfulness, and self-compassion.

In the intervention made by Hevezi et al. [31], an individual session was done with each of the participants to work on aspects about compassion fatigue, satisfaction with compassion, burnout, self-care, and mindfulness. Each participant received a CD with different short-term meditations to demonstrate that stress reduction and cultivating self-compassion does not involve too much time. Oncology nurses decreased their compassion fatigue and burnout scores and increased their compassion satisfaction.

Jakel et al. [32] conducted a study to evaluate the effect of an intervention carried out through a mobile app called PRMA to promote resilience in oncology nurses. The period of monitoring the use of the mobile app was for six weeks since the participants downloaded it.

In the study by Potter et al. [34], a resilience program was applied to educate nurses in compassion fatigue and chronic stress, with a duration of four sessions of 90 min each, held during working hours. The scores in compassion satisfaction, burnout, and secondary traumatic stress improved after the program.

In the study conducted by Zajac et al. [33], oncology nurses were helped by conducting support sessions after the death of a patient. There were no statistically significant differences between preand post-intervention scores.

Finally, Yilmaz et al. [35] found that a nurses-led intervention program with two sessions about compassion fatigue, coping methods, oncology patients, breathing exercises, baksi dance, mandala painting, relaxation, and questions about death and empathy and two counselling follow-ups with motivational messages via a smartphone was effective in reducing compassion fatigue and burnout and increasing compassion satisfaction. 


\subsection{Meta-Analysis}

The study sample for the meta-analysis was $n=5$ studies, with a total oncology nursing sample of $n=900$. All the studies included in the meta-analysis used the same questionnaire, the ProQOL, for the evaluation of compassion satisfaction, burnout, and compassion fatigue.

The Egger lineal regression test did not show publication bias in any meta-analysis $(p>0.05)$. The $I^{2}$ heterogeneity analysis result was $96.8 \%$ for compassion satisfaction, $95 \%$ for burnout, and $97 \%$ for compassion fatigue.

The meta-analytic estimation with a 95\% confidence interval for low compassion satisfaction, as shown in Figure 2, was 19\% (5-39\%). Figure 3 shows medium and high levels of burnout, with a prevalence rate of $56 \%(38-74 \%)$. The medium and high compassion fatigue prevalence rates were $60 \%$ (37-81\%), as shown in Figure 4.

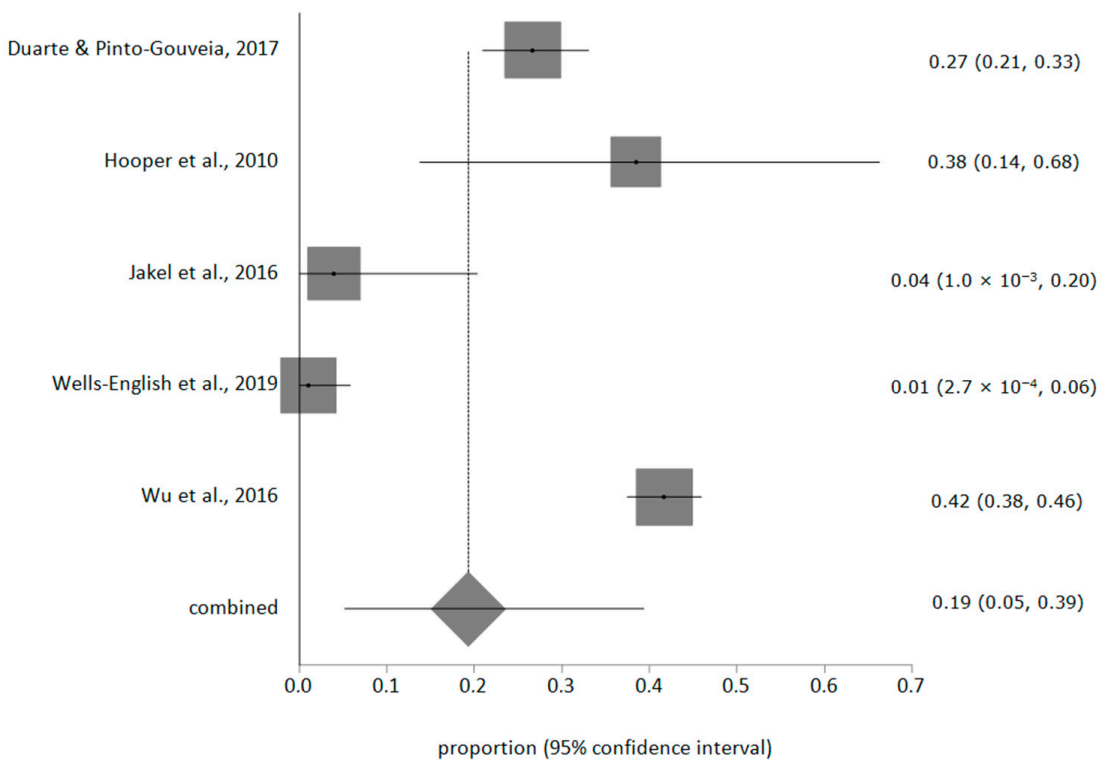

Figure 2. Prevalence rate of low compassion satisfaction.

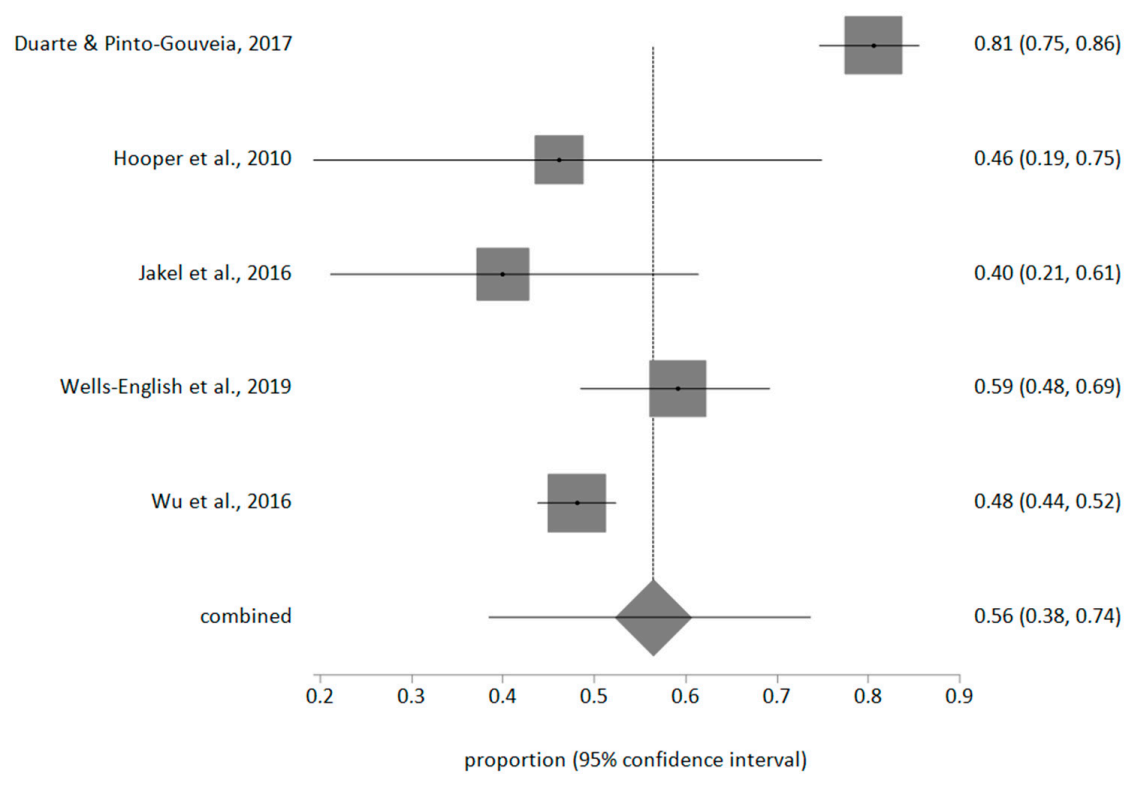

Figure 3. Prevalence rate of medium and high burnout. 


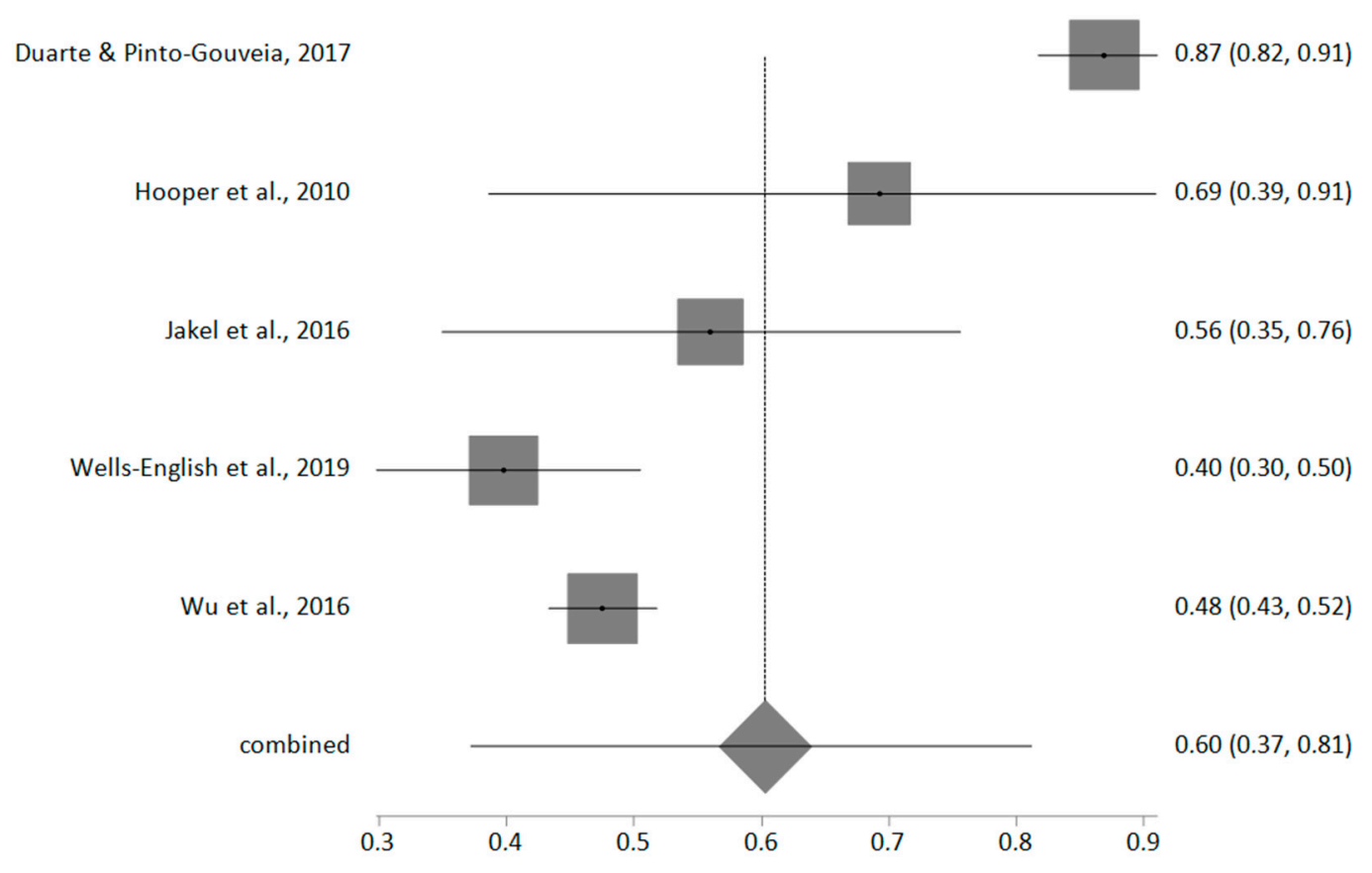

Figure 4. Prevalence rate of medium and high compassion fatigue.

\section{Discussion}

The aim of this systematic review was to analyze the levels and prevalence of compassion fatigue, compassion satisfaction, and burnout in oncology nurses and interventions for its treatment. The ProQOL (Professional Quality of Life) was the instrument used by the included studies for data collection because it includes elements that other burnout scales do not examine, like compassion fatigue [18]. Compassion fatigue is not measured in other burnout instruments widely used, like the Maslach Burnout Inventory [2,36] or the Copenhagen Burnout Inventory (CBI), which is centered on burnout related to person, work, and client treatment [37]. The ProQOL focuses on elements that detect the quality of life of the individual and how it is projected in different aspects of their life.

One of the main factors that may affect nurses in oncology units in terms of compassion fatigue is the excessive emotional workload. A clear example in this unit is the constant contact with situations of pain, suffering, and death in patients and family members [16]. Another study suggests that nurses who are more prone to compassion fatigue are usually more self-judgmental and have less psychological flexibility [23], which can affect nursing care.

One of the solutions found in the studies to reduce burnout and compassion fatigue in oncology nurses is the practice of mindfulness. After a month following a mindfulness program, participants saw their satisfaction for compassion improved and their burnout reduced [38]. Mindfulness helps nurses to reduce the perceived stress and emotional tension from their daily contact with patients in a delicate state of health and this type of program has shown that it can improve nurses' personal well-being and in return, according to their perception, can help prevent the development of compassion satisfaction burnout [39]. Some investigations have shown that daily meditation can reduce the effects of compassion fatigue and secondary traumatic stress, increasing compassion satisfaction by reducing stress and anxiety, giving greater clarity of thoughts and feelings, greater intelligence, and greater compassion, gratitude, inner peace, and quality of life $[40,41]$. Thus, promoting mindfulness and meditation can improve how nurses feel about their job and prevent compassion satisfaction and burnout development.

Furthermore, research showed that group support sessions are a great benefit to educate, help, and exchange experiences in which both patients and health personnel can benefit from anxiety reduction, and a sense of empowerment and confidence to face situations with greater conviction [42]. 
In addition to the mentioned programs, the examination of new technologies for the prevention of burnout has been a novel proposal. Technologies, such as mobile applications, have been used with mindfulness, a very effective approach in reducing this syndrome [36]. The application offers a simple and flexible introduction to the practice of mindfulness and can also increase work commitment, job satisfaction, innovation and creativity, and self-efficacy [43]. This kind of intervention can implemented more easily by nursing managers to prevent burnout and as most nurses in the world have a mobile phone.

This study has some limitations. Only studies with an oncology nursing sample were included because their work and daily tasks are different from other healthcare professionals and a meta-analysis with mixed samples would not be valid for various professions. Finally, the study aim was centered mainly on compassion fatigue because it is an important growing problem in oncology units due to the characteristics of the patients.

\section{Conclusions}

Compassion fatigue and burnout are the main affected areas in oncology nurses while low compassion satisfaction is less prevalent. The constant exposure to risk situations at work is an important factor in preventing and applying programs that will help to improve compassion satisfaction and minimize compassion fatigue.

The use of tools for assessing compassion satisfaction and burnout in oncology nurses is a great benefit to detect and treat possible consequences at a psychological or physical level in this population. In fact, with proper evaluation and the development of appropriate intervention programs, the number of cases of burnout and compassion fatigue cases in oncology nurses could be prevented and minimized, which would produce better care and better health outcomes for the patients, higher satisfaction for nurses with their work, and less symptoms of burnout headache, insomnia, and irritability.

Author Contributions: Conceptualization, E.O.-C., G.A.C.-d.1.F., L.A.-G. and J.L.G.-U.; Data curation, E.O.-C., K.V.-R., A.V.-S., G.A.C.-d.1.F., L.A.-G. and J.L.G.-U.; Formal analysis, E.O.-C., A.V.-S., L.A.-G. and J.L.G.-U.; Funding acquisition, E.O.-C., G.A.C.-d.l.F. and L.A.-G.; Investigation, E.O.-C., K.V.-R., A.V.-S. and L.A.-G.; Methodology, E.O.-C., L.A.-G. and J.L.G.-U.; Project administration, E.O.-C., G.A.C.-d.1.F. and J.L.G.-U.; Resources, A.V.-S. and G.A.C.-d.1.F.; Software, A.V.-S. and J.L.G.-U.; Supervision, N.S.-M. and G.A.C.-d.1.F.; Validation, N.S.-M.; Visualization, K.V.-R., N.S.-M. and G.A.C.-d.l.F.; Writing-Original draft, K.V.-R. and N.S.-M.; Writing-Review \& editing, K.V.-R., N.S.-M. and J.L.G.-U. All authors have read and agreed to the published version of the manuscript.

Funding: This research received no external funding.

Conflicts of Interest: The authors declare no conflict of interest.

\section{References}

1. Gascon, S.; Leiter, M.P.; Andrés, E.; Santed, M.A.; Pereira, J.P.; Cunha, M.J.; Albesa, A.; Montero-Marín, J.; García-Campayo, J.; Martínez-Jarreta, B. The role of aggressions suffered by healthcare workers as predictors of burnout. J. Clin. Nurs. 2013, 22, 3120-3129. [CrossRef] [PubMed]

2. Maslach, C.; Jackson, S.E. The measurement of experienced Burnout. J. Organ. Behav. 1981, 2, 99-113. [CrossRef]

3. Schaufeli, W.B.; Leiter, M.P.; Maslach, C. Burnout: 35 years of research and practice. Career Dev. Int. 2009, 14, 204-220. [CrossRef]

4. World Health Organization. Burn-Out an "Occupational Phenomenon": International Classification of Diseases. Available online: https://www.who.int/mental_health/evidence/burn-out/en/ (accessed on 18 December 2019).

5. Cañadas-De la Fuente, G.A.; Vargas, C.; San Luis, C.; García, I.; Canadas, G.R.; De la Fuente, E.I. Risk factors and prevalence of Burnout syndrome in the nursing profession. Int. J. Nurs. Stud. 2015, 52, $240-249$. [CrossRef] [PubMed]

6. Gómez-Urquiza, J.L.; De la Fuente-Solana, E.I.; Albendín-García, L.; Vargas-Pecino, C.; Ortega-Campos, E.; Cañadas-De la Fuente, G.A. Prevalence of Burnout Syndrome in Emergency Nurses: A Meta-Analysis. Crit. Care Nurse 2017, 37, e1-e9. [CrossRef] 
7. Vargas, C.; Cañadas, G.A.; Aguayo, R.; Fernández, R.; De la Fuente, E.I. Which occupational risk factors are associated with Burnout in nursing? A meta-analytic study. Int. J. Clin. Health Psychol. 2014, 14, $28-38$. [CrossRef]

8. Pradas-Hernández, L.; Ariza, T.; Gómez-Urquiza, J.L.; Albendín-García, L.; De la Fuente, E.I.; Cañadas-De la Fuente, G.A. Prevalence of burnout in paediatric nurses: A systematic review and meta-analysis. PLoS ONE 2018, 13, e0195039. [CrossRef]

9. De la Fuente-Solana, E.I.; Suleiman-Martos, N.; Pradas-Hernández, L.; Gomez-Urquiza, J.L.; Cañadas-De la Fuente, G.A.; Albendín-García, L. Prevalence, Related Factors, and Levels of Burnout Syndrome Among Nurses Working in Gynecology and Obstetrics Services: A Systematic Review and Meta-Analysis. Int. J. Environ. Res. Public Health 2019, 16, 2585. [CrossRef]

10. López-López, I.M.; Gómez-Urquiza, J.L.; Cañadas, G.R.; De la Fuente, E.I.; Albendín-García, L.; Cañadas-De la Fuente, G.A. Prevalence of burnout in mental health nurses and related factors: A systematic review and meta-analysis. Int. J. Ment. Health Nurs. 2019, 28, 1032-1041. [CrossRef]

11. Cañadas-de la Fuente, G.A.; Albendín-García, L.; Cañadas, G.R.; San Luis-Costas, C.; Ortega-Campos, E.; De la Fuente-Solana, E.I. Nurse burnout in critical care units and emergency departments: Intensity and associated factors. Emergencias 2018, 30, 328-331.

12. Cañadas-De la Fuente, G.A.; Gómez-Urquiza, J.L.; Ortega-Campos, E.; Cañadas, G.R.; Albendín-García, L.; De la Fuente-Solana, E.I. Prevalence of burnout syndrome in oncology nursing: A meta-analytic study. Psychooncology 2018, 27, 1426-1433. [CrossRef] [PubMed]

13. De la Fuente Solana, E.I.; Cañadas, G.R.; Ramirez Baena, L.; Gómez Urquiza, J.L.; Ariza, T.; Cañadas De la Fuente, G.A. An Explanatory Model of Potential Changes in Burnout Diagnosis According to Personality Factors in Oncology Nurses. Int. J. Environ. Res. Public Health 2019, 16, 312. [CrossRef] [PubMed]

14. De la Fuente Solana, E.I.; Gómez Urquiza, J.L.; Cañadas, G.R.; Albendín García, L.; Ortega Campos, E.; Cañadas De la Fuente, G.A. Burnout and its relationship with personality factors in oncology nurses. Eur. J. Oncol. Nurs. 2017, 30, 91-96. [CrossRef] [PubMed]

15. Gómez-Urquiza, J.L.; Aneas-López, A.B.; Fuente-Solana, E.I.; Albendín-García, L.; Díaz-Rodríguez, L.; Cañadas-De la Fuente, G.A. Prevalence, Risk Factors, and Levels of Burnout Among Oncology Nurses: A Systematic Review. Oncol. Nurs. Forum. 2016, 43, E104-E120. [CrossRef]

16. Van Mol, M.M.; Kompanjie, E.J.; Benoit, D.D.; Baker, J.; Nijkamp, M.D. The prevalence of compassion fatigue and Burnout among healthcare professionals in intensive care units: A systematic review. PLoS ONE 2015, 10, eO136955. [CrossRef]

17. Joinson, C. Coping with compassion fatigue. Nursing 1992, 22, 116-120.

18. Stamm, B.H. The Concise ProQOL Manual. 2010. Available online: https://proqol.org/uploads/ ProQOLManual.pdf (accessed on 20 December 2019).

19. Dempsey, C.; Reilly, B.A. Nurse engagement: What are the contributing factors for success? Online J. Issues Nurs. 2016, 21, 2.

20. Moher, D.; Shamseer, L.; Clarke, M.; Ghersi, D.; Liberati, A.; Petticrew, M.; Shekelle, P.; Stewart, L.A. Preferred Reporting Items for Systematic Review and Meta-Analysis Protocols (PRISMA-P) 2015 statement. Syst. Rev. 2015, 4, 1. [CrossRef]

21. Oxford Centre for Evidence-Based Medicine (OCEBM). Levels of Evidence; University of Oxford: Oxford, UK, 2010.

22. Al-Majid, S.; Carlson, N.; Kiyohara, M.; Faith, M.; Rakovski, C. Assessing the Degree of Compassion Satisfaction and Compassion Fatigue Among Critical Care, Oncology, and Charge Nurses. J. Nurs. Adm. 2018, 48, 310-315. [CrossRef]

23. Duarte, J.; Pinto-Gouveia, J. The role of psychological factors in oncology nurses' burnout and compassion fatigue symptoms. Eur. J. Oncol. Nurs. 2017, 28, 114-121. [CrossRef]

24. Hooper, C.; Craig, J.; Janvrin, D.R.; Wetsel, M.A.; Reimels, E. Compassion satisfaction, Burnout, and compassion fatigue among emergency nurses compared with nurses in other selected inpatient specialties. J. Emerg. Nurs. 2010, 36, 420-427. [CrossRef] [PubMed]

25. Jang, I.; Kim, Y.; Kim, K. Professionalism and professional quality of life for oncology nurses. J. Clin. Nurs. 2016, 25, 2835-2845. [CrossRef] [PubMed] 
26. Mooney, C.; Fetter, K.; Gross, B.W.; Rinehart, C.; Lynch, C.; Rogers, F.B. A preliminary analysis of compassion satisfaction and compassion fatigue with considerations for nursing unit specialization and demographic factors. Int. J. Trauma Nurs. 2017, 24, 158-163. [CrossRef]

27. Wells-English, D.; Giese, J.; Price, J. Compassion Fatigue and Satisfaction: Influence on Turnover among Oncology Nurses at an Urban Cancer Center. Clin. J. Oncol. Nurs. 2019, 23, 487-493. [CrossRef]

28. Wu, S.; Singh-Carlson, S.; Odell, A.; Reynolds, G.; Su, Y. Compassion Fatigue, Burnout, and Compassion Satisfaction among Oncology Nurses in the United States and Canada. Oncol. Nurs. Forum. 2016, 43, E161-E169. [CrossRef] [PubMed]

29. Yu, H.; Jiang, A.; Shen, J. Prevalence and predictors of compassion fatigue, Burnout and compassion satisfaction among oncology nurses: A cross-sectional survey. Int. J. Nurs. Stud. 2016, 57, 28-38. [CrossRef]

30. Duarte, J.; Pinto-Gouveia, J. Effectiveness of a mindfulness-based intervention on oncology nurses' Burnout and compassion fatigue symptoms: A non-randomized study. Int. J. Nurs. Stud. 2016, 64, 98-107. [CrossRef]

31. Hevezi, J.A. Evaluation of a meditation intervention to reduce the effects of stressors associated with compassion fatigue among nurses. J. Holist. Nurs. 2016, 34, 343-350. [CrossRef]

32. Jakel, P.; Kenney, J.; Ludan, N.; Miller, P.S.; McNair, N.; Matesic, E. Effects of the Use of the Provider Resilience Mobile Application in Reducing Compassion Fatigue in Oncology Nursing. Clin. J. Oncol. Nurs. 2016, 20, 611-616. [CrossRef]

33. Zajac, L.M.; Moran, K.J.; Groh, C.J. Confronting Compassion Fatigue: Assessment and Intervention in Inpatient Oncology. Clin. J. Oncol. Nurs. 2017, 21, 446-453.

34. Potter, P.; Deshields, T.; Berger, J.A.; Clarke, M.; Olsen, S.; Chen, L. Evaluation of a compassion fatigue resiliency program for oncology nurses. Oncol. Nurs. Forum. 2013, 40, 180-187. [CrossRef]

35. Yılmaz, G.; Üstün, B.; Günüşen, N.P. Effect of a nurse-led intervention programme on professional quality of life and post-traumatic growth in oncology nurses. Int. J. Nurs. Pract. 2018, 24, e12687. [CrossRef] [PubMed]

36. Ramirez-Baena, L.; Ortega-Campos, E.; Gomez-Urquiza, J.L.; Cañadas-De la Fuente, G.R.; De la Fuente-Solana, E.I.; Cañadas-De la Fuente, G.A. A Multicentre Study of Burnout Prevalence and Related Psychological Variables in Medical Area Hospital Nurses. J. Clin. Med. 2019, 8, 92. [CrossRef] [PubMed]

37. Kristensen, T.S.; Borritz, M.; Villadsen, E.; Christensen, K.B. The Copenhagen Burnout Inventory: A new tool for the assessment of burnout. Work Stress 2005, 19, 192-207. [CrossRef]

38. Slatyer, S.; Craigie, M.; Heritage, B.; Davis, S.; Rees, C. Evaluating the Effectiveness of a Brief Mindful Self-Care and Resiliency (MSCR) Intervention for Nurses: A Controlled Trial. Mindfulness 2017, 9, 534-546. [CrossRef]

39. Gracia-Gracia, P.; Oliván-Blázquez, B. Burnout and Mindfulness Self-Compassion in Nurses of Intensive Care Units. Holist. Nurs. Pract. 2017, 31, 225-233. [CrossRef]

40. Bonamer, J.; Aquino-Russell, C. Self-Care Strategies for Professional Development. J. Nurses Prof. Dev. 2019, 35, 93-97. [CrossRef]

41. Perkins, J.; Aquino-Russell, C. Graduate Nurses Experience the Sacred During Transcendental Meditation. Int. J. Hum. Caring 2017, 21, 163-171. [CrossRef]

42. Hu, A. Reflections: The Value of Patient Support Groups. Otolaryngol. Head Neck Surg. 2017, 156, 587-588. [CrossRef]

43. Möltner, H.; Leve, J.; Esch, T. Burnout-Prävention und mobile Achtsamkeit: Evaluation eines appbasierten Gesundheitstrainings bei Berufstätigen. Das Gesundh. 2017, 57, 295-300. [CrossRef]

(C) 2019 by the authors. Licensee MDPI, Basel, Switzerland. This article is an open access article distributed under the terms and conditions of the Creative Commons Attribution (CC BY) license (http://creativecommons.org/licenses/by/4.0/). 